(C) 2020, The Authors. Published by Elsevier Inc. and Fass Inc. on behalf of the American Dairy Science Association ${ }^{\circledR}$. This is an open access article under the CC BY-NC-ND license (http://creativecommons.org/licenses/by-nc-nd/4.0/).

\title{
Perspectives of western Canadian dairy farmers on the future of farming
}

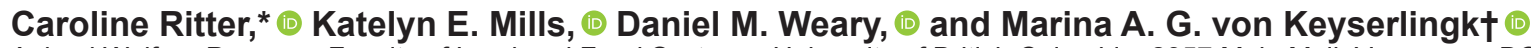 \\ Animal Welfare Program, Faculty of Land and Food Systems, University of British Columbia, 2357 Main Mall, Vancouver, BC, V6T 1Z6 Canada
}

\begin{abstract}
Similar to the situation in many countries, the dairy industry in Canada is challenged by the need to adapt to changing societal demands. An industry-led initiative (Dairy Farmers of Canada's proAction Initative, known as proAction) was developed to respond to this challenge, providing mandatory national standards for on-farm practices. Farmers are more likely to follow such standards if they are aligned with their values and beliefs. The aim of this study was to better understand farmers' perspectives on the future of the Canadian dairy industry, with a focus on the role of mandatory policies such as those related to proAction. Seven focus groups were conducted, with discussions based on the principles of appreciative inquiry. Participants were each asked to write down key words that represent the "must-haves" on dairy farms in 20 yr from now. Although participants were encouraged to focus on aspects directly related to animal care, all answers were accepted. Key words were then used to facilitate a discussion and elicit ideas on how to achieve these must-haves. Particular focus was on the direction that participants believed policy should take to meet these goals. Explorative qualitative analysis was used for the written key words, and transcripts of the audiorecorded focus group discussions were analyzed using thematic analysis. Examples of farm-specific considerations that were raised as future must-haves of animal care on dairy farms included cow comfort, employee management, responsible health management, and use of advanced thechnologies. Participants agreed that objectives can only be achieved through collaboration among farmers and between farmers and researchers, and they regarded citizen education as a promising approach to align differing expectations of the public and farmers. Citizen trust in the dairy industry was considered a must-have, and participants believed that one of the benefits of mandatory policies for animal care is
\end{abstract}

Received February 26, 2020.

Accepted July 11, 2020.

*Current address: Department of Health Management, Atlantic Veterinary College, University of Prince Edward Island, 550 University Ave., Charlottetown, PE, C1A 4P3 Canada.

†Corresponding author: marina.vonkeyserlingk@ubc.ca their potential to increase trust. These results may help guide the development of new animal care policies and increase understanding of the perceived legitimacy of new policies by dairy farmers.

Key words: dairy cattle welfare, policy development, dairy farm management, social license to farm, public opinion

\section{INTRODUCTION}

Dairy farming has undergone substantial changes in the past few decades (Barkema et al., 2015). For example, in Canada there were approximately 20,000 dairy farms with milk shipments in 1999; 20 yr later this number dropped to 10,000 farms, with the number of dairy cows remaining relatively stable (CDIC, 2019). This trend, along with related changes such as increased automation, is expected to continue (Britt et al., 2018). Further, the quality of life of dairy cattle is receiving increased attention (Britt et al., 2018), including interest in questions about access to pasture (Schuppli et al., 2014; Kühl et al., 2019), early cow-calf separation (Ventura et al., 2013), and pain management (Wolf et al., 2016; Cardoso et al., 2017). When common management practices on farm fail to resonate with societal values, the social license to farm may be in jeopardy.

Raedts et al. (2017) suggested that system experts (e.g., dairy farmers) are valuable consultants for identifying future challenges and opportunities. Identification of challenges can be done through consultation processes, industry-led initiatives, and participatory research designs (including those affected by the issue in the research process; Baum et al., 2006; Jagosh et al., 2012). Fraser (2014) argued that industry initiatives will be more successful when led by the producers. For example, a reported lack of trust by farmers in the National Milk Producers Federation animal care program (i.e., Farmers Assuring Responsible Management program; FARM) was based on their perception that "outsiders" were running the program (Rink et al., 2019); the farmers argued that they should be given more opportunities for input.

In Canada, the dairy industry has developed standards for dairy cattle care as part of the Dairy Farmers of Canada's proAction Initative (proAction; DFC- 
NFACC, 2018). ProAction consists of 6 modules (milk quality, food safety, animal care, traceability, environmental sustainability, and biosecurity), all containing standards that dairy producers must adhere to. To our knowledge, no research has assessed how Canadian dairy farmers perceive the role of these mandatory policies.

Lam et al. (2017) examined a variety of strategies to decrease antibiotic use on dairy farms, and found that regulations alone were only effective in changing behavior if there was coercion or enforcement in place. This may be especially true when stakeholders do not believe that the regulations steer the industry in the right direction. To improve the effectiveness of efforts to change dairy practices, policies should be aligned with farmers' values and norms (Lam et al., 2017).

The aim of our research was to assess farmers' views on the future of the dairy industry, including "musthaves" of farms in $20 \mathrm{yr}$ from now in terms of animal care. Farmers were asked to identify opportunities for how best to achieve these must-haves, with a special focus on the role that policy should play.

\section{MATERIALS AND METHODS}

This study was approved by the ethics board of the University of British Columbia (H18-02880). Data collection took place in March and April 2019.

\section{Data Collection}

Focus groups $(\mathrm{n}=7)$ were conducted with a convenience sample of farmers; the number of participants per group ranged from 3 to 5 (25 participants in total). Five focus groups were held at the annual Western Canadian Dairy Seminar (Red Deer, Alberta, Canada) in March 2019, and 2 focus groups where conducted during a research information day at The University of British Columbia, Dairy Education and Research Centre (Agassiz, BC, Canada) in April 2019. Consent forms were signed directly before the recorded discussions.

Researchers recruited participants by handing out flyers during the events. Flyers contained information on the research study and the scheduled times and locations of the focus groups. Any dairy producer (19 yr of age or older) was eligible. It was not possible to determine how many farmers were informed about the research but decided not to participate. However, some farmers said that they were unwilling to participate either because of lack of interest or competing events at the conference. Participants were divided into separate, groups of similar sizes. Discussions were held at the event venues. Each group was interviewed separately by 1 researcher (although in 1 case, a second researcher observed the discussion).

Focus groups were facilitated by 4 female researchers (3 senior PhD students, 1 postdoctoral fellow) from The University of British Columbia. All facilitators had undergraduate and graduate education related to the dairy industry and experience conducting focus groups or interviews with dairy farmers. Their practical experience varied from spending time on a commercial dairy farm for a few days to having lived on a farm for several years conducting different chores such as milking and calf care. Additionally, 1 researcher had a veterinary degree with veterinary experience working in the dairy industry. All facilitators were asked to provide feedback in the design of the semistructured question guide (Figure 1) before the focus groups. Each facilitator participated in a 90-min training session to ensure that they were prepared and that expectations were aligned with the aim of the study. The question guide was used by all facilitators to ensure that all aspects of interest were covered, although facilitators had the freedom to rephrase or add probing questions if the conversation stalled or was veering off course.

Appreciative Inquiry. The principles of appreciative inquiry were used to design and guide the semistructured discussion with farmers. Appreciative inquiry as a research approach is believed to motivate people to see the present and future in a positive light, instead of focusing on the negatives of a current situation or the difficulties in achieving a goal in the future (Reed, 2007). According to this approach, what people do today is guided by their view of the future. One aim of appreciative inquiry is to ask questions that stimulate ideas and create possibilities for action (Hung et al., 2018). Instead of asking participants about current shortfalls in the dairy industry, the focus was on the must-haves of dairy cattle care in the future and how identified must-haves can be achieved.

Focus groups lasted between 41 and 70 min (averaging $50 \mathrm{~min}$ ) and consisted of 2 parts: key words and semistructured discussion.

Key Words. After an introduction, focus group participants were asked to write 3 to 5 key words or phrases on sticky notes reflecting what they considered to be the must-haves in regards to animal care for dairy farms $20 \mathrm{yr}$ from now. While the facilitator asked participants to focus on aspects related to animal care, all answers were allowed and considered. Then, the sticky notes were laid out in the middle of the table for everyone to review, identify similarities and differences in the answers, and comment on other participants' ideas. The rationale for this approach was to (1) ensure that every participant contributed their view on the musthaves, (2) provide starting points for a discussion about 


\section{Sticky notes}

When you think of dairy farms in 20 years from now: Please write down some of your "must-haves" in terms of animal care (3-5 key words or phrases).

\section{Semi-structured discussion}

1) Dairy farm characteristics of the future

- Why do you think these "must-haves" are important?

- Now that you have identified these "must-haves", how do we go about making sure that this happens?

- Referring to the sticky notes: How can "most commonly identified themes" be achieved?

- What do you think other people not associated with the Canadian dairy industry expect in terms of dairy cattle care in 20 years?

- How can we align their expectations and your expectations?

2) The role of policies

- What role does policy play in your farming practice?

- Which policies for animal care should be voluntary versus mandatory, and why?

- To what extent might nation-wide standards (e.g. proAction, Code of Practice) be beneficial for reaching the "must-haves"?

- Should milk from farms that don't meet these standards be mixed with milk from other farms? - Why/why not?

- How could nationwide standards affect the image of the Canadian dairy industry?

- To what extent might these standards affect consumers and their buying decisions?

- To what extent could these standards help distinguish Canada from other countries? Why?

\section{3) Closing}

- Are there any final comments you would like to make?

Figure 1. Semistructured question guide used for 7 focus groups to assess Canadian dairy farmers' views of the future of dairy farms and the role of policies in achieving the "must-haves." Primary questions are indicated by a solid black bullet point, whereas secondary questions are indicated by a white bullet point.

the must-haves of dairy farms, and (3) gain insight into the importance of these must-haves based upon the frequency of key words.

Semistructured Discussion. The semistructured question guide was used to expand on the key words from the sticky notes as a group. The question guide included primary questions, which were used by facilitators to initiate discussion on a specific topic, and secondary questions, which were used to obtain additional information or could be used as prompts if necessary (Figure 1). During the first part of the discussion, specific focus was on why farmers regarded the must-haves as important and how they thought these must-haves could be achieved. If not already brought up in the discussion by the participants, the facilitator would then steer the discussion toward the role of farm-specific and national policies (e.g., proAction) in achieving the must-haves. If facilitators felt that the discussion strayed from the main topic of interest, they would either ask participants to provide an explanation to the relevance of the discussion (e.g., clarify the link between employee management and animal care) or would restate the initial question with the request to remain on topic.

\section{Analysis}

Key Words. Exploratory qualitative analysis of the key words that participants had written on the sticky notes was conducted to create a word cloud (Cidell, 2010). Words that did not yield useful information or were nonspecific (e.g., per, the, more) were removed. 
Words that occurred in singular and plural form were combined, and only the singular form was used. Negative phrasing (e.g., tiestall phase out) was displayed together in the word cloud to avoid misinterpretation. An online software tool (wordclouds.com, Vianen, the Netherlands) was used for creating the word cloud.

Semistructured Discussion. Focus group audiorecordings were transcribed verbatim by a professional transcription service, and transcripts were checked for accuracy. The first author (C. R.) coded the transcripts from a deductive perspective using the following a priori questions. (1) What are the must-haves of dairy farms in 20 years? (2) How can these must-haves be achieved? (3) What role should nationwide mandatory policies play in achieving the must-haves?

The initial intention was to use the research questions as 3 a priori themes. However, after starting the coding process, we discovered that distinguishing between the first 2 themes was not possible. Therefore, the approach was changed for the first 2 research questions, and an inductive approach was used to analyze the transcripts and develop overarching themes. Using thematic analysis, meaningful text passages were abstracted into codes and, using an iterative process, the obtained codes were revised and grouped according to similarities and differences (Miles et al., 2014). During analysis, memoing was used to capture thoughts and reflections about the data (Miles et al., 2014), which facilitated organization and interpretation of the findings.

The coding process resulted in a codebook that summarized assigned themes, codes, and definitions (DeCuir-Gunby et al., 2011). The codebook was forwarded to the second author (K. M.), who assigned codes to 2 transcripts based on her understanding of the text and the definitions provided in the codebook. Then, codes were compared between the 2 coders, differences identified and discussed, and the codebook adjusted accordingly. After the codebook was updated, a similar process was done with 2 additional transcripts. Then, as a last step, the codebook was used by both coders to code 2 final transcripts, and intercoder reliability was assessed by calculating the Cohen's Kappa coefficient using NVivo (QSR International Pty Ltd., version 12; https://www.qsrinternational.com/nvivo-qualitative -data-analysis-software/home).

For reporting of the results, unique identifiers (e.g., P2_4) were assigned to quotes from participating farmers with the first number representing the focus group (1-7) and the second number representing the participant within this group (1-5). Square brackets (i.e., $[\ldots])$ were used to indicate when a quote was shorted or when we inserted explanatory information to ensure the meaning of the quote was maintained.

\section{RESULTS}

Participants were from 3 different western Canadian provinces (BC, $\mathrm{AB}, \mathrm{MB})$; additionally, 1 farmer was from Ontario. All participants were male. Median herd size was 146 milking cows (ranging from 40-1,000 cows). The analysis of the written key words resulted in 95 different words or short phrases (135 in total; Figure 2 ). The word (cow) comfort was used most frequently (8 times), followed by consumer (4 times), biosecurity (2 times), management (3 times), employees (2 times), quality ( 3 times), and stall (3 times).

Four distinct themes resulted from the thematic analysis of the focus group discussions as follows: (1) farm-specific must-haves for dairy farms in the future, (2) the necessity of using a joint effort to reach the must-haves, (3) the influence of the public on the directions of the dairy industry, and (4) the role and limitations of nationwide policies and regulations to achieve the must-haves. The Cohen's Kappa coefficient (representing intercoder reliability) was 0.69 , which Landis and Koch (1977) classified as substantial agreement.

\section{Farm-Specific Must-Haves for Dairy Farms in the Future}

All groups addressed farm-specific considerations. Cow comfort was mentioned as an important requirement for future dairy farms. Specifically, participants referred to comfortable bedding and flooring, enough space, suitable facilities, cleanliness, air quality, and equipment such as cow brushes. Participants argued that tiestalls should not exist 20 yr from now. One participant (P2_1) said, "Even if [the cows] are only going to be in there in the winter and only be let out in the summer, I don't think that's right, either." Other participants regarded outdoor access as infeasible due to the price of land and practical challenges in granting access. Some participants were hesitant about group housing of calves because of the financial implications of restructuring their barns and perceived health benefits of individual housing. However, one participant (P1_3) suggested, "I think though, what should be made clear to the producer is that there are [...] monetary advantages to raising your animals in groups of 2 and 3, just about competitive learning, that there actually is a business case to be made for building like that."

Participants also discussed care and welfare during major life events of the animals. Although they generally did not believe the practice of cow-calf separation needed to be addressed (P2_1 said, "There is a reason why farmers [remove the calf from the dam]"), they were 


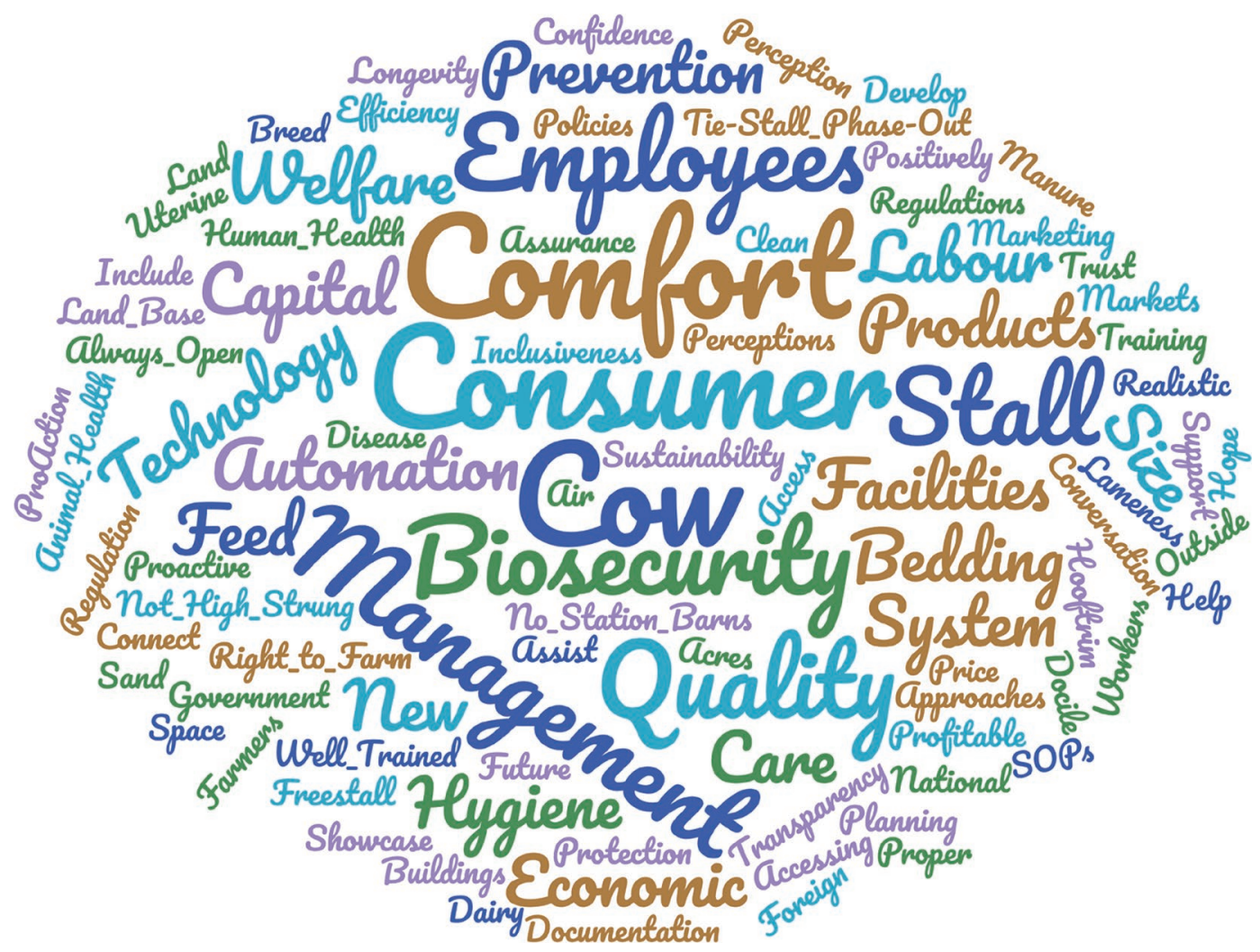

Figure 2. Word cloud representing key words and phrases that dairy farmers wrote in answer to the question of what they thought are the "must-haves" of dairy farms $20 \mathrm{yr}$ from now in terms of animal care. Words in larger font were mentioned more frequently (coloring is random).

critical about animal care before and during transport. To this point, P5_1 said, "[... the animals] go for a full 3 days in a row," and P5_4 added, "It's just wrong."

Health management for the entire herd was a topic that came up in all focus groups. In particular, participants believed that biosecurity measures were crucial to ensure that diseases were treated or prevented early and efficiently. The need for more prudent use of antibiotics to reduce antimicrobial resistance was discussed; however, participants assumed that antibiotics would still play a role in treatment of infections in $20 \mathrm{yr}$ from now. A participant (P7_2) stated, "[...] because if you're helping to cure [the disease], you're removing pain and suffering [...]. When the rubber meets the road, I need to be able to treat a cow."

One participant suggested that improved genetics might help reduce antimicrobial use by making animals more relisient to disease; others felt that longevity has to be increased using improved genetics. However, one participant (P7_1) argued that producers already cull animals based on "the least amount of potential" when the farm reaches its quota. Genetics was also considered to be important in terms of animal temperament.
One participant (P1_3) explained that cows will have to be compatible with automation, stating, "[...] with coming into a new [robotic milking] barn, I don't think there's any room for high strung cows."

Many participants regarded technology and automation (especially automatic milking systems) as important must-haves on dairy farms 20 yr from now. Participants believed that new applications of technology, such as algorithms to better detect mastitis and predicting pregnancy, would become more useful. One reason for increased reliance on technology was that labor would likely be increasingly difficult to find; one participant (P5_3) stated, "[...] because labour is an issue, so we will see that we go more towards automation." Employee management was a main point of interest for participants; they agreed that with growing farm size, the ability of farm owners to manage and train personnel will be an important must-have. One participant (P4_3) stated, "[...] but if you have more people properly trained working on a farm, then obviously you're gonna have better welfare for the animals because they're all getting a little bit more attention." The issue of hiring foreign workers was discussed, as 
one participant (P5_2) said, "[...] but if you're forced to go out of this country because people don't want to take the job, there's something wrong. That's something we'll have to deal with."

Standard operating procedures were generally regarded as must-haves to ensure consistent care of animals on farm while allowing room for farm-specific differences. One participant (P2_1) explained, "I think that's important, that when I'm not there that [the employees] are caring for my animals the same way I would when I am there."

Participants believed that fair salaries would be necessary to retain personnel, and that incentives would be a useful tool to motivate employees to take good care of the animals. In addition to the example of the commonly used approach of offering a financial bonus for low bulk-tank SCC, one participant (P3_2) suggested, "You could get something measurable with regard to the calf rearing and give [the employee] an incentive based on something that's measurable." Similarly, participants believed in the benefit of incentivizing farm owners financially to meet the must-haves, for example, by providing premiums for quality milk or grazing cows on pasture.

Participants emphasized that money is necessary to make on-farm changes and meet the must-haves of farms in $20 \mathrm{yr}$. As such, farms need to ensure that they will be profitable, which was linked with farm size "[...] because the small [farms] just don't survive," a participant (P5_3) explained. However, it was also suggested that some farmers could focus on specialty products. Some argued that terminating supply management would encourage creativity among farmers such as expanding into niche markets (e.g., specialized butters), but others felt that "Supply management is preferable, because that's a system that we're used to," as one participant (P5_4) stated.

\section{Requirement of a Joint Effort to Reach the Must-Haves}

When discussed, all participants agreed that meeting future must-haves can only be achieved with a collective effort, including collaborations among farmers and between farmers and researchers. Specifically, participants suggested that different producer associations should collaborate more and that farmers can learn from each other. For example, one participant (P6_2) said, "Whenever anybody builds a new barn, they obviously put a lot of work into it, and a lot of effort and thinking in a lot of things, but they always end up regretting something because there's not that information available to them [...] we need some kind of online database or something."
Participants also discussed the challenges of peers who have little ambition to meet the must-haves. As an example, one participant (P6_3) said, "[...] and there are rotten apples out there, but they shouldn't farm because they make us look bad." Some participants highlighted that farmers should not be afraid to confront these peers "in a very proactive, $[. .$.$] in a non-$ judgemental [way]," as an example (P1_1). However, participants also realized that there are limitations to peer pressure and that regulations might be necessary to facilitate change.

All groups discussed, and agreed upon, the importance of research in achieving must-haves. Participants distinguished between informal research that they conduct themselves on farms (e.g., trial and error) and data collected by researchers affiliated with universities. One participant (P1_3) said, "You know, we are here today because it was innovation and science to get us to robots, or parallel parlours [...]," but he also remarked: "[...] but I think, unfortunately, in this dairy sector, there is a lot of preconceived notions. I'm doing what my dad did, and that science does not play that large a role in [farmers'] business decisions." Participants highlighted that longstanding relationships with researchers help to create credibility and trust, which fosters communication and can enhance uptake of scientific recommendations. Some participants believed that researchers have to do a better job communicating their findings to farmers, but it was also highlighted that, as one participant (P2_1) said, "[...] farmers have to be openminded to new ideas. These new technologies are not going to happen unless [researchers] can test them on farms." Whereas participants agreed that policies to achieve the must-haves should be based on science, they cautioned that these policies should only be developed by people who have knowledge of the practical aspects of dairy farming. One participant (P4_1) asked, "How can somebody be telling me how to do my job who's never done my job?"

Although the focus of participants was on farmers and researchers, other stakeholders that can aid in achieving the must-haves of dairy farms in $20 \mathrm{yr}$ were also mentioned. Specifically, participants referenced equipment suppliers and builders for barn design, nutritionists and veterinarians for advice on farm management, milk processors for the promotion of dairy products, and pharmaceutical companies for developing replacements to antibiotics.

\section{Influence of the Public on the Directions of the Dairy Industry}

One consistent theme that emerged was public interest in animal care. As one participant (P6_3) summa- 
rized, "[...] it changed into: how is [the dairy product] produced? Now it's about the farmer behind it, and [...] what is your animal welfare status? And I think that is going to be more and more in the next 20 years for sure, more and more in the picture." As such, participants argued that a must-have of dairy farms will be to meet public expectations regarding animal care. However, participants generally felt that the public was ignorant of farm practices and that some expectations, such as pasture access, were unreasonable. However, some participants mentioned potential compromises. One participant (P7_1) added, "I feel like we will give [the public] the dry cows at some point, or something, or some heifers. Try and hold them off." Nonetheless, participants believed that there should be a limit to what influence the public has on farm practices. For example, one participant (P6_3) stated, "We need sales, so we have to address the concerns, but we have to be careful how far we want to push it." Another participant (P6_4) argued that some members of the public will never be satisfied, "The extreme activists, there's no-I don't think there [is] any appeasing them."

Participants suggested that education and transparency are the best approaches to achieve public trust. On this topic, one participant (P7_2) said, "I feel like in the next 20 years, education's going to be a big point." Participants suggested several ways of connecting to public education, including providing information through schools, social media, radio shows, and open farm days, as well as by being a part of the community and seeking conversations. However, they also saw risks with being transparent because the public might misinterpret the information provided. For example, one participant (P5_2) saw risks with posting dairy farming content on social media and stated, "An average dairy farmer will do more damage by having a blog or by being on Facebook."

Whereas most participants were convinced that education is the way forward in achieving public trust, some were concerned, cautioning that the public will only educate themselves on what they are interested in and dairy farming might not be a topic of interest. Furthermore, participants did not agree on what kind of message would be needed to reach the public. For example, whereas one participant (P5_4) stated, "Science and facts, I think, need to play a pretty big role to combat negative influences on products." Another participant (P5_2) disagreed, saying, "I don't think facts are that important. I think emotions are a lot more important," and suggested to use "compelling stories" to reach the public. Similarly, instead of just relying on facts and education, one participant (P7_2) suggested emphasizing the close relationship that farmers have with their animals, stating, "I think we'll need to rebrand ourselves a little bit differently. [...] We are not just corporate. We're all people that actually do work on our farms. We're like artisans."

\section{Policy and Regulations}

Participants were asked to what extent policies such as proAction could help achieve the must-haves on dairy farms. Overall, participants believed regulations to be beneficial. An example stated by a participant (P6_3) was, "It's like traffic. If there's no rules, it's chaos." They especially thought it was important that regulations were industry-driven, and one participant (P1_3) stated, "I'd rather do the regulating than have someone come in and tell me how to regulate." They also agreed that, in general, standards have to be mandatory to have an effect. However, participants emphasized that a certain degree of flexibility was necessary to account for farm-specific differences. To account for different farming styles, one participant (P7_1) believed that it was advantageous to have health and welfare outcome measures instead of specific design requirements and stated, "It's probably better to be more strict on lameness incidence in your herd and have that as some kind of a benchmark." Similarly, in some of the focus groups it was highlighted that regulations have to be feasible in terms of what can be expected from farmers in regard to required expenses and timelines. One of the participants (P7_1) explained, "If [regulations] put too much pressure on too quickly, all of a sudden you've gotta do this, you've gotta do this, it'll become reactionary and it won't be logical. [...] and that's not what you want. You actually want people to have time to think about it and figure out how they're gonna do it." Additionally, it was mentioned that farmers felt pressured by industry and government to meet continuously increasing demands. One participant (P4_2) shared, "We're at the point now where we can't really handle anything anymore. Nothing can be stricter than it is now right now."

Participants appreciated that national regulations provide consistency. For farmers with very poor management (i.e., the "bad apples"), participants regarded regulations as an effective way to define a minimum standard. Examples of enforcement methods included financial penalties, refusal to pick up milk, and shutting the farm down. However, limitations of policies were also expressed (P3_1) such as, "I have not yet to this day, seen a poor farmer that was made into good farmer because a policy was put in place. [...]. Eventually, you just had to weed them out." Although participants highlighted that good farmers will likely not have to 
change much of their management to comply with the regulations, they criticized the amount of paperwork that is required for proAction.

Participants appreciated the guidance provided by proAction and felt that it could foster collaboration between farmers and farm advisers. One participant (P2_1) expressed, "[proAction] almost forced the dairy producer to have a good relationship with his veterinarian and other nutritionists and stuff, too, to help them with that." They especially regarded on-farm assessments as beneficial, with a participant (P2_3) who stated, "We are identifying problems on each farm, tailored to that farm," and highlighted that these assessments can alert farmers to issues that they were unaware of.

One of the advantages of national regulations is to increase public confidence in the dairy industry, directly addressing the must-have of social license. One of the participants (P3_1) stated, "The consumer today demands proof. They demand proof, and [proAction] is their way of getting proof." Participants strongly believed that increased public confidence would benefit the Canadian dairy producers by distinguishing their dairy products from other countries' products. One of the participants (P1_3) explained, "Over time, [the consumers] will recognize what we're doing and how we're doing it, and that will play a role in their buying decision." However, some participants believed that there should be more and better marketing for Canadian dairy products. In addition to the limited public awareness of proAction, another perceived limitation was the price of dairy products. As one participant (P7_2) stated, "Everyone has lots of virtues [...] until they go shopping and they buy the cheapest thing."

\section{DISCUSSION}

Although we asked participants to focus on the issue of animal care when formulating must-haves, the ensuing discussions addressed a wider variety of issues, potentially due to the different interests of farmers. However, it became apparent that many of the discussed themes were indirectly linked to animal care on farms, including how employee management and incentives can affect the attention and care that animals receive. This finding is in line with the concept of "One Welfare," which argues that animal welfare and human well-being should be regarded as complementary (Pinillos et al., 2016).

Generally, participants seemed to have trouble thinking beyond the present-day challenges that they currently experienced, perhaps indicating that farmers are not used to being consulted on such topics. When discussing participatory approaches to antimicrobial stewardship, Reyher et al. (2017) suggested that farmers have difficulties coming up with solutions because they are not used to taking ownership of the topic. Kok (2014) recommended that planning of health interventions should include consultations with all stakeholders, including the target population. Although Kok (2014) referred to human health interventions, this notion likely holds true for interventions to improve animal health and welfare; in the case of regulations affecting dairy farms, the target is the individual dairy farmer. Thus, there is merit in allowing broader representation of farmers, other than just elected board members, when developing industry-led standards. In addition to the development of standards, involving farmers and other stakeholders in participatory research has the potential to create more sustainable outcomes (Jagosh et al., 2012). With a few exceptions (e.g., van Dijk et al., 2017; using participatory policy-making approach to allow UK dairy farmers to be partners in developing an antimicrobial stewardship initiative), most participatory research of this nature in agriculture has taken place in developing countries (Knook et al., 2018). For example, Mapfumo et al. (2013) described the benefits of participatory action research for overcoming climate change challenges for small-holder dairy farmers in Africa.

In addition to the arguably more apparent farmspecific must-haves that participants mentioned, a dominant theme was the issue of meeting public expectations for animal care. Participants generally believed educating the public was the most suitable approach to bringing citizen expectations into line with farm practices. Similarly, Dutch pig farmers defended their current management instead of considering the citizens' perspective as valid (Benard and de Cock Buning, 2013). Attempts to educate citizens are generally regarded as ineffective in changing a person's values (Ventura et al., 2016). Benard and de Cock Buning (2013) concluded that 1-way information reflecting farmer values is likely to fail in improving public acceptance; instead, shared learning experiences and exploring common ground between farmers and citizens would likely be more successful.

Canadian farmers participating in this study appeared to be favorable of the proAction program, possibly because it was developed by producers (DFCNFACC, 2018). In contrast, US farmers commented on unfavorable aspects related to the development and implementation of the FARM program (that was largely developed by milk processors), expressing anger and frustration over their limited opportunity for input (Rink et al., 2019). Participants especially regarded on-farm assessments, such as those conducted by proAction, as beneficial, and agreed that assessments can 
lead to increased awareness of issues that were previously overlooked. Similarly, Rink et al. (2019) reported that $59 \%$ of US dairy farmers felt that they had a good working relationship with their FARM evaluator. Despite positive attitudes toward proAction, this study highlights the importance of setting realistic goals and timelines when implementing industry programs. Trying to meet expectations that are perceived to be unrealistic can be a stressor, and may lead to giving up the pursuit (Locke and Latham, 2013).

As we analyzed each of the 7 focus groups, fewer new themes emerged, suggesting that we had achieved data saturation. Previous studies using focus groups indicate that 5 to 8 groups is sufficient (Kirchberger et al., 2009; Coenen et al., 2012), although the number of participants per group was relatively low in the current study (3-5 farmers per group). Having multiple facilitators could be viewed as a limitation of the current study, as each facilitator approached the study with their own positionality and familiarity with the topic. The semistructured question guide was used to mitigate the risk of influencing answers, and researchers met before data collection began to discuss these concerns. Participants in our study were mainly from the western provinces of Canada (although 1 was from ON and had traveled to the event), and there is variation in farming practices across the country. Furthermore, participants were recruited at dairy events (i.e., an industry conference and a research information day), and it is possible that they were more progressive in their thinking than farmers who do not typically attend these types of event. However, this study was not intended to be generalizable in the positivist, quantitative tradition (Carminati, 2018), and we do not make claims regarding a larger population. However, we believe that the results of this research add to the growing conversation about the future of the dairy industry.

Future research should examine these issues in a broader range of farmers, including those working in different countries and in different sectors of animal production. Further potential avenues for future research include assessing the perceptions of other stakeholders in the supply chain and exploring avenues to facilitate communication among stakeholders (e.g., dairy producers and citizens).

\section{CONCLUSIONS}

The findings of this study revealed how the perceived must-haves of good animal care in the present and future are closely related to other aspects of dairy farming such as employee management and profitability. Farmers agreed that collaborative efforts and mandatory policies are important to achieve these objectives.
However, there was uncertainty to what extent public expectations should shape the future of the dairy industry.

\section{ACKNOWLEDGMENTS}

Caroline Ritter was supported by a Government of Canada Banting Post-Doctoral Fellowship (Ottawa, ON, Canada). Funding for Katelyn Mills was provided by the Social Science and Humanities Research Council of Canada (SSHRC; Ottawa, ON, Canada) Doctoral Fellowship and the Canadian Dairy Commission (CDC; Ottawa, ON, Canada) Scholarship. Additional funding for this project was provided by the Hans Sigrist Research Prize (Bern, Switzerland) awarded to Marina von Keyserlingk. General funding for the UBC's Animal Welfare Program is provided by Canada's Natural Sciences and Engineering Research Council Industrial Research Chair Program awarded to MvK and DMW with contributions from Alberta Milk (Edmonton, AB), British Columbia Dairy Association (Burnaby, BC), Boehringer Ingelheim (Burlington, ON), CanWest DHI (Guelph, ON), BC Cattle Industry Development Fund (Kamloops, BC), Dairy Farmers of Canada (Ottawa, ON), Dairy Farmers of Manitoba (Winnipeg, MB), Intervet Canada Corporation (Kirkland, QC), Saputo Inc. (Montreal, QC), SaskMilk (Regina, SK), and Semex Alliance (Guelph, ON). The authors have not stated any conflicts of interest.

\section{REFERENCES}

Barkema, H. W., M. A. G. von Keyserlingk, J. P. Kastelic, T. J. G. M. Lam, C. Luby, J.-P. Roy, S. J. LeBlanc, G. P. Keefe, and D. F. Kelton. 2015. Invited review: Changes in the dairy industry affecting dairy cattle health and welfare. J. Dairy Sci. 98:7426-7445. https://doi.org/10.3168/jds.2015-9377.

Baum, F., C. MacDougall, and D. Smith. 2006. Participatory action research. J. Epidemiol. Community Health 60:854-857. https://doi .org/10.1136/jech.2004.028662.

Benard, M., and J. T. de Cock Buning. 2013. Exploring the potential of dutch pig farmers and urban-citizens to learn through frame reflection. J. Agric. Environ. Ethics 26:1015-1036. https://doi.org/ 10.1007/s10806-013-9438-y.

Britt, J. H., R. A. Cushman, C. D. Dechow, H. Dobson, P. Humblot, M. F. Hutjens, G. A. Jones, P. S. Ruegg, I. M. Sheldon, and J. S. Stevenson. 2018. Invited review: Learning from the future-A vision for dairy farms and cows in 2067. J. Dairy Sci. 101:3722-3741. https://doi.org/10.3168/jds.2017-14025.

Cardoso, C. S., M. A. G. von Keyserlingk, and M. J. Hötzel. 2017. Brazilian citizens: Expectations regarding dairy cattle welfare and awareness of contentious practices. Animals (Basel) 7:89. https:// doi.org/10.3390/ani7120089.

Carminati, L. 2018. Generalizability in qualitative research: A tale of two traditions. Qual. Health Res. 28:2094-2101. https://doi.org/ $10.1177 / 1049732318788379$.

CDIC (Canadian Dairy Information Centre). 2019. Dairy farming in Canada. Number of farms, dairy cows and heifers. Accessed Feb. 16, 2020. https://www.dairyinfo.gc.ca/index_e.php?s1=dff-fcil\&s2 =farm-ferme\&s $3=\mathrm{nb}$. 
Cidell, J. 2010. Content clouds as exploratory qualitative data analysis. Area 42:514-523. https://doi.org/10.1111/j.1475-4762.2010 $.00952 . x$.

Coenen, M., T.A. Stamm, G. Stucki, and A. Cieza. 2012. Individual interviews and focus groups in patients with rheumatoid arthritis: A comparison of two qualitative methods. Qual. Life Res. 21:359370. https://doi.org/10.1007/s11136-011-9943-2.

DeCuir-Gunby, J. T., P. L. Marshall, and A. W. McCulloch. 2011. Developing and using a codebook for the analysis of interview data: An example from a professional development research project. Field Methods 23:136-155. https://doi.org/10.1177/1525822X10388468.

DFC-NFACC (Dairy Farmers of Canada). 2018. ProAction-Leading the way for sustainable dairy farming. Accessed Feb. 2, 2020. https://www.dairyfarmers.ca/Media/Files/proaction/proaction ang_lr15.pdf.

Fraser, D. 2014. Could animal production become a profession? Livest. Sci. 169:155-162. https://doi.org/10.1016/j.livsci.2014.09.017.

Hung, L., A. Phinney, H. Chaudhury, P. Rodney, J. Tabamo, and D. Bohl. 2018. Appreciative inquiry: Bridging research and practice in a hospital setting. Int. J. Qual. Methods 17:160940691876944. https://doi.org/10.1177/1609406918769444.

Jagosh, J., A. C. Macaulay, P. Pluye, J. Salsberg, P. L. Bush, J. Henderson, E. Sirett, G. Wong, M. Cargo, C. P. Herbert, S. D. Seifer, L. W. Green, and T. Greenhalgh. 2012. Uncovering the benefits of participatory research: Implications of a realist review for health research and practice. Milbank Q. 90:311-346. https://doi.org/10 $.1111 /$ j.1468-0009.2012.00665.x.

Kirchberger, I., M. Coenen, F. Hierl, C. Dieterle, J. Seissler, G. Stucki, and A. Cieza. 2009. Validation of the International Classification of Functioning, Disability and Health (ICF) core set for diabetes mellitus from the patient perspective using focus groups. Diabet. Med. 26:700-707. https://doi.org/10.1111/j.1464-5491.2009.02762 .x.

Knook, J., V. Eory, M. Brander, and D. Moran. 2018. Evaluation of farmer participatory extension programmes. J. Agric. Educ. Ext. 24:309-325. https://doi.org/10.1080/1389224X.2018.1466717.

Kok, G. 2014. A practical guide to effective behavior change: How to apply theory- and evidence-based behavior change methods in an intervention. Health Psychol. Rev. 16:156-170.

Kühl, S., S. Gauly, and A. Spiller. 2019. Analysing public acceptance of four common husbandry systems for dairy cattle using a picture-based approach. Livest. Sci. 220:196-204. https://doi.org/10 .1016/j.livsci.2018.12.022.

Lam, T. J. G. M., J. Jansen, and R. J. Wessels. 2017. The RESET mindset model applied on decreasing antibiotic usage in dairy cattle in the Netherlands. Ir. Vet. J. 70:5. https://doi.org/10.1186/ s13620-017-0085-x.

Landis, J. R., and G. G. Koch. 1977. The measurement of observer agreement for categorical data. Biometrics 33:159-174. https://doi .org/10.2307/2529310.

Locke, E. A., and G. P. Latham. 2013. New Developments in Goal Setting and Task Performance. Routledge/Taylor and Francis Group, New York, NY.

Mapfumo, P., S. Adjei-Nsiah, F. Mtambanengwe, R. Chikowo, and K. E. Giller. 2013. Participatory action research (PAR) as an entry point for supporting climate change adaptation by smallholder farmers in Africa. Environ. Dev. 5:6-22. https://doi.org/10.1016/ j.envdev.2012.11.001.

Miles, M. B., A. M. Huberman, and J. Saldaäna. 2014. Qualitative Data Analysis: A Methods Sourcebook. 3rd ed. Sage Publications Inc., Thousand Oaks, CA.

Pinillos, R. G., M. C. Appleby, X. Manteca, F. Scott-Park, C. Smith, and A. Velarde. 2016. One welfare - A platform for improving human and animal welfare. Vet. Rec. 179:412-413. https://doi.org/ $10.1136 / v r .15470$

Raedts, P. J. M., S. C. Garcia, D. F. Chapman, G. R. Edwards, N. Lane, and R. P. Rawnsley. 2017. Is systems research addressing the current and future needs of dairy farms? Anim. Prod. Sci. 57:1311-1322. https://doi.org/10.1071/AN16647.

Reed, J. 2007. Appreciative Inquiry: Research for Change. Sage Publications Inc., Thousand Oaks, CA.

Reyher, K. K., D. C. Barrett, and D. A. Tisdall. 2017. Achieving responsible antimicrobial use: Communicating with farmers. In Pract. 39:63-71.

Rink, K. A., P. Turk, S. L. Archibeque-Engle, H. Wilmer, J. K. Ahola, J. C. Hadrich, and I. N. Roman-Muniz. 2019. Dairy producer perceptions of the farmers assuring responsible management (FARM) animal care program. J. Dairy Sci. 102:11317-11327. https://doi .org/10.3168/jds.2019-16859.

Schuppli, C. A., M. A. G. von Keyserlingk, and D. M. Weary. 2014. Access to pasture for dairy cows: Responses from an online engagement. J. Anim. Sci. 92:5185-5192. https://doi.org/10.2527/ jas.2014-7725.

van Dijk, L., A. Hayton, D. C. J. Main, A. Booth, A. King, D. C. Barrett, H. J. Buller, and K. K. Reyher. 2017. Participatory policy making by dairy producers to reduce anti-microbial use on farms. Zoonoses Public Health 64:476-484. https://doi.org/10.1111/zph .12329.

Ventura, B. A., M. A. G. von Keyserlingk, C. A. Schuppli, and D. M. Weary. 2013. Views on contentious practices in dairy farming: The case of early cow-calf separation. J. Dairy Sci. 96:6105-6116. https: //doi.org/10.3168/jds.2012-6040.

Ventura, B. A., M. A. G. von Keyserlingk, H. Wittman, and D. M. Weary. 2016. What difference does a visit make? Changes in animal welfare perceptions after interested citizens tour a dairy farm. PLoS One 11:e0154733. https://doi.org/10.1371/journal.pone .0154733.

Wolf, C. A., G. T. Tonsor, M. G. S. McKendree, D. U. Thomson, and J. C. Swanson. 2016. Public and farmer perceptions of dairy cattle welfare in the United States. J. Dairy Sci. 99:5892-5903. https:// doi.org/10.3168/jds.2015-10619.

\section{ORCIDS}

Caroline Ritter @ https://orcid.org/0000-0001-7349-5241

Katelyn E. Mills (ib https://orcid.org/0000-0001-7296-9214

Daniel M. Weary @ https://orcid.org/0000-0002-0917-3982

Marina A. G. von Keyserlingk ( ) https://orcid.org/0000-0002-1427 $-3152$ 